Working Paper

Series
${ }_{1}$ IIIIIFINRISK

National Centre of Competence in Research Financial Valuation and Risk Management

National Centre of Competence in Research

Financial Valuation and Risk Management

Working Paper 373

\title{
Property Derivatives and Index-Linked Mortgages
}

\author{
J uerg Syz Paolo Vanini
}

Marco Salvi

First version: February 2006

Current version: August 2006

This research has been carried out within the NCCR FINRISK project on

"Credit Risk and Non-Standard Sources of Risk in Finance" 


\title{
Property Derivatives and Index-Linked Mortgages*
}

August 31, 2006

\author{
Juerg Syz, Paolo Vanini, Marco Salvi \\ Zurich Cantonal Bank, Switzerland
}

(First version: February 2006; This version: August 31, 2006)

\footnotetext{
${ }^{*}$ We are grateful to Aydin Akguen, Zeno Bauer, Andries Diener, Thomas Domenig, Silvan Ebnoether, Philipp Halbherr, Patrik Schellenbauer, Roger Wiesendanger and Tyler Yang for many valuable discussions and comments. Paolo Vanini acknowledges the support from the Swiss National Center of Competence FINRISK and the Swiss Finance Institute (SFI).
} 


\title{
Property Derivatives and Index-Linked Mortgages
}

\begin{abstract}
Economists have forcefully argued for the introduction and use of property derivatives as a hedge against house price risk (e.g. Shiller and Weiss, 1999). The rationale for these financial instruments seems clear, as many households are heavily invested in housing and standard financial instruments offer a poor hedge. In practice, however, most of the property derivatives available have been targeted to meet the needs of institutional investors, not those of owner-occupiers. Building on the recent launch of the first Swiss property derivative, we here propose index-linked mortgages tailored to retail consumers. The payments of these mortgages depend on the corresponding housing market performance. We further discuss the stabilization of the homeowner's net wealth, price the instruments, and quantify the expected decrease in the mortgage default risk achieved by these immunization effects.
\end{abstract}

Keywords: House Price Risk; Mortgage Default Risk; Rent or Buy; Hedonic Index.

JEL Classification: D14, G10, G21, R31 


\section{Introduction}

Owner-occupier households are typically heavily exposed to house price fluctuations and have no chance to unload this risk. This may lead to suboptimal allocations for the households. Englund, Hwang and Quigley (2002) show that most Swedish homeowners, up to an age of 50, hold a strongly unbalanced portfolio. Flavin and Yamashita (2002) report similar findings for the US, where households below 30 years of age invest more than three times their net wealth in housing.

In this paper, we propose, describe and price a new type of mortgage that enables homeowners to reduce their housing risk exposure substantially. The basic idea is to link the mortgage to an index of house prices. More precisely, the interest payments and/or the principal are linked to the underlying index movements and not - as is common - to the evolution of interest rates. Hence, the mortgage is no longer an interest rate but a house price derivative. If, for example, house prices drop, the households have either to pay lower interest on their mortgage or, alternatively, the price decrease is directly subtracted from the mortgage's principal at maturity. In both cases the volatility of a household's home equity is lessened. Hence, this type of property derivative reduces the homeowner's exposure to house price risk while reducing the credit risk exposure of the bank through asset-liability immunization. Index-linked mortgages thus provide Pareto improvements by allocating collateral risk more optimally and by reducing the number of default and related costs.

The recent findings of Iacoviello and Ortalo-Magné (2003) support our approach. These authors investigate the benefits of giving households the chance to adjust their portfolio holdings through the use of property derivatives. They show that hedging can greatly improve welfare, especially for the case of poorer homeowners who face the highest net wealth volatility and shortfall risk. According to Englund at al. (2002) those living in the rented sector would equally benefit from gaining access to housing index investments. Real estate stocks do not represent a reasonable alternative to index instruments; since they are mainly driven by interest rates and do not adequately represent the market for owner-occupied housing. 
A second, older stream of research that supports our findings goes back to Baesel and Biger (1980) and Statman (1982). Baesel and Biger (1980) describe a situation in which homeowners prefer a mortgage linked to an inflation index over a fixed rate one. Statman (1982) extends the Baesel-Biger model by introducing housing values as a further variable of choice. In his model, the utility of the homeowner depends on two key elements. The first element is the relationship between the rate of change in labor income and the inflation rate. The second is the relationship of the inflation rate and the changes in the net value of houses. Linking the mortgage to a house price index (instead of to inflation) provides a higher correlation to the price of the house under consideration, thus further enhancing utility.

Our approach, however, differs from the proposals of Case, Shiller and Weiss (1993) who suggested the introduction of futures contracts tied to regional house price indices. In practice, it might be difficult for poorer households to enter into short positions, as required by these kinds of contracts. Nonetheless, poorer households typically face the highest leverage, i.e. their investment portfolio may be significantly unbalanced. In contrast, in our approach households do not need to enter into short positions because the mortgage is directly linked to a property derivative.

In our approach, the quality, credibility and transparency of the underlying price index plays a crucial role. We use a transaction-based, hedonic index of the greater Zurich area that has passed both the credibility and transparency tests. Indeed, for the first time in Switzerland, property derivatives linked to this index were successfully launched in February 2006.

Our paper is organized as follows. We first provide a rationale for property derivatives used in index-linked mortgages. We then consider the design of index-linked mortgages with regard to liquidity constraints and discuss the impact of these mortgages on credit quality. Next, we assess the appropriateness and the limitations of using property derivatives as a hedge for individual housing. Finally, we price index-linked mortgages and compare their price and sensitivities with standard mortgages. We support our findings with corresponding data, mainly focusing on the Swiss property market. 


\section{Index-Linked Mortgages}

Most homeowners carry a very high amount of property risk. This may be due to a lack of risk perception, as owner-occupied housing may be regarded exclusively for the consumption stream it generates. However, even risk-savvy homeowners lack financial instruments enabling them to unload housing risk. Furthermore, the very households likely to benefit most from hedging instruments, as they have to bear the lumpiest risk in housing, tend to be the comparatively less affluent. These households have typical difficulties in accessing over-the-counter hedge contracts. It thus appears reasonable to integrate the hedging instruments in mortgages, so that all homeowners with leveraged housing risk could automatically access housing riskmanagement techniques. Moreover, the expected loss on the mortgage is reduced because of the housing hedge. Hence the mortgagee can benefit directly from a reduced credit spread on the "index-linked mortgage". Throughout the paper, we exclusively consider recourse mortgages, as they are common in Switzerland and in Europe.

\subsection{Rent or Buy?}

Today's standard decision when it comes to housing is commonly referred to as "rent or buy". In other words, an individual either carries a large, lumpy property risk (usually leveraged by mortgage financing), or she rents and is thus not exposed to any property risk. ${ }^{1}$

Considering property risk in a portfolio context, it makes sense for a homeowner to partially unload the property risk, while those living in the rented sector might reasonably take on some property risk.

We consider a homeowner's overall financial situation. A typical homeowner finances her house partly with a mortgage that comes with fixed nominal and fixed or floating interest payments. In addition, she may also hold securities such as stocks or bonds in her investment portfolio. Still, the exposure to housing may easily exceed total net wealth, as long as the liability, i.e. the mortgage, is not linked to the price of the property. The result for the

\footnotetext{
${ }^{1}$ In Switzerland, the market we look at, the (upward) adjustment of rents is heavily regulated and is rarely driven by property performance.
} 
homeowner is a poorly diversified overall portfolio. An index-linked mortgage is used to offset housing exposure and therefore contributes significantly to a more efficient portfolio allocation.

The following example illustrates the risk associated with current property financing that leads to a suboptimal portfolio allocation.

Let us imagine that a Swiss-based homeowner buys a house in the Canton of Zurich in 1994, at a price of CHF 500'000. He takes on a 5 year mortgage with a notional amount of CHF 400'000 and put down CHF 100'000 in equity. In addition, he owns a portfolio consisting of various liquid assets amounting to CHF 60'000. We suppose that within 5 years, house prices in the region decline by $15 \%$ and so does the value of his house, which is then worth only CHF 425'000. After the said 5 years, the mortgage is due and the house value is reassessed. The bank offers a renewed $80 \%$ mortgage finance, i.e. is willing to provide CHF 340'000. Since the due mortgage amounts to CHF 400'000, the difference of CHF 60'000 needs to be paid out of his other funds. All things being equal, the adverse development of house prices leaves him with zero liquid assets and home equity of CHF $85^{\circ} 000$, i.e. his net wealth has almost halved.

If he had financed his house with a mortgage linked to the local house price index, e.g. by including a put option, his net wealth would have been stabilized considerably. Instead of losing $15 \%$ on the total house value, he would only incur a loss on the equity part of the house plus the cost of the put option of, say, $3.5 \%$ on the mortgage's notional amount. ${ }^{2}$ This would leave him with a net wealth position of CHF 131'000 instead of CHF 85'000, of which CHF 46 '000 is liquid assets.

In short, he would have reduced his housing exposure from $312.5 \%$ of net wealth to $62.5 \%$, which is a much more reasonable level. But still, the share invested in housing might be too high to achieve optimal diversification. As a result of reducing the risk, the bank may grant a higher borrowing level, which in turn unloads even more housing risk and makes funds available for investments in other asset classes to further optimize the homeowner's overall portfolio. In this sense, index-linked mortgages greatly improve the risk profile and welfare of many households.

\footnotetext{
${ }^{2}$ See section 4 on pricing
} 


\begin{tabular}{rrrrrrr}
\hline 1985 - 2005 & Return p.a. & Standard Dev. p.a. & \multicolumn{3}{c}{ Correlation Matrix } & \\
\cline { 3 - 6 } & & & Stocks & Bonds & Cash & House Prices \\
\hline Stocks & 11.01 & 17.79 & 1.000 & & & \\
Bonds & 5.41 & 5.53 & 0.105 & 1.000 & & \\
Cash & 3.75 & 1.35 & -0.075 & 0.140 & 1.000 & \\
House Prices & 6.48 & 7.56 & -0.163 & -0.051 & 0.048 & 1.000 \\
\hline
\end{tabular}

Table 1

The first two moments and the correlations of all involved assets. We use the MSCI Switzerland for stocks, the 10-year Swiss Government Bond Index for bonds, the J.P.Morgan Switzerland 3-month Cash Index for cash and the Index for owner-occupied housing in the Canton of Zurich ZWEX for house prices. All numbers are based on quarterly observations during the period from Q4 1985 to Q4 2005.

Figure 1 shows the impact on a homeowner's portfolio if the housing asset class is considered. Due to the low correlation of its returns with those of traditional assets, the housing asset class is attractive for diversification. We focus on the first two moments and the correlations of all involved assets, as displayed in Table 1.

The figure shows on an unlevered basis the risk/return situation of a buyer's portfolio (100\% invested in the house), of a renter's portfolio (100\% invested in an optimized portfolio containing stock, bonds and cash) and of a portfolio with a partial exposure to a property, optimized in context with the other investable assets. Besides the usual caveats of the standard mean-variance portfolio approach, we ignore differences in liquidity between housing and other assets, as well as considerations connected to the fact that housing is held not only as an investment but also for the housing service stream it generates. To make housing returns comparable with pure investment assets, we include a net rent yield that corresponds to the saved rental expense, net of maintenance cost.

In this setup, portfolio risk can be reduced considerably using a combined portfolio. In the context of portfolio theory, any risk-averse individual should invest along the efficient frontier to maximize utility. For a given level of return, the homeowner (who has invested all her wealth in the house) bears a risk in terms of standard deviations of almost $8 \%$ p.a.. The person living in rented accommodation, on the other hand, invests in an efficient portfolio consisting of tradable assets. This leaves her with standard deviations of $6 \%$ p.a.. However, she has zero 


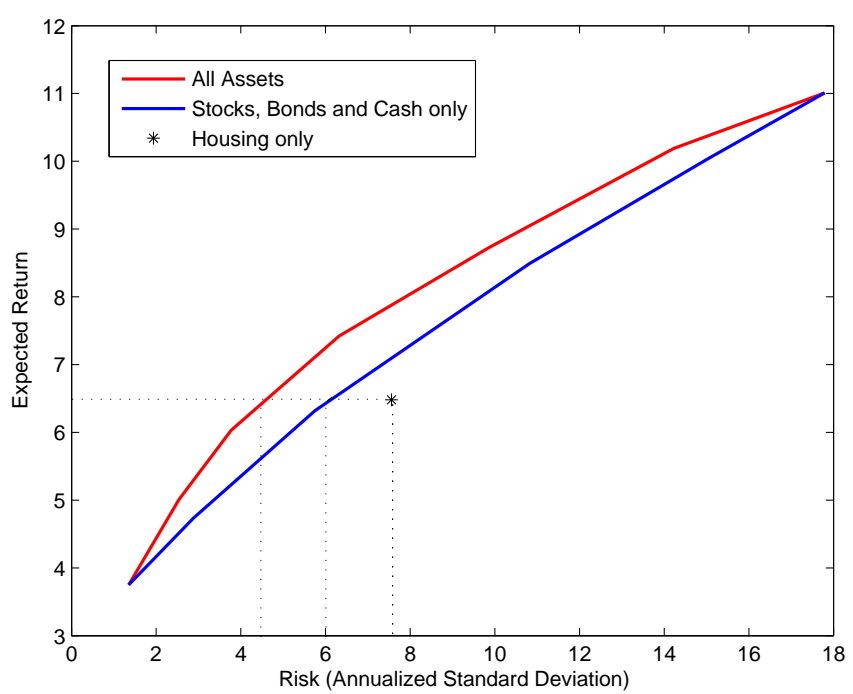

Fig. 1. Combining the house with other assets is superior to renting or buying. Returns, variances and correlations are based on quarterly observations during the period from Q4 1985 to Q4 2005. Again, we use the MSCI Switzerland for stocks, the 10-year Swiss Government Bond Index for bonds, the J.P.Morgan Switzerland 3-month Cash Index for cash and the Index for owner-occupied housing in the Canton of Zurich ZWEX for house prices. The cash and bond indices are calculated as total returns. To obtain the total returns of the stock and the housing index, we include the average income component, i.e. the net dividend respectively net rent yield, over the corresponding 20-year period.

percent invested in housing. With a partial investment in both housing and the liquid asset portfolio, risk is around $4.5 \%$.

\subsection{Designed to Avoid Liquidity Constraints}

Homeowners' characteristics are typically very heterogeneous. Their mortgage financing decisions as well as their risk affinity depend upon their net wealth as well as on their income streams and borrowing constraints (Campbell, 2006). As such, the design of the mortgage is crucial when it comes to liquidity constraints and solvency risk of individual homeowners.

We propose two basic designs of index-linked mortgages to address liquidity risk. For the first design, we keep the principal on the mortgage fixed, but link the interest payment to the development of house prices. The interest payments of this index-floating mortgage are 
calculated by adding the periodic index performance to a base rate, e.g. $3.5 \%$ p.a., within a predefined bandwidth. If the index falls, the due payment is reduced to a given floor level, say $1.5 \%$ p.a.. Hence, the homeowner is able to save $2 \%$ on the mortgage's nominal amount per year. On the other hand, if the index increases, the payment is adjusted upward up to a cap level of say $5.0 \%$ p.a.. ${ }^{3}$ Thereby, the maximum a homeowner can save is $2 \%$ per year, in other words an accumulated $10 \%$ over a 5 year period. Given low volatility, this approach absorbs the housing risk well. In contrast to traditional floating mortgages, such index-floating mortgages trigger higher payments only when housing prices actually rise. The cap at $5.0 \%$ p.a. avoids an interest-payment liquidity constraint and the accumulated $10 \%$ savings serve as a cushion against the refinancing liquidity constraint. To avoid the borrower spending the savings, a custodian account or direct periodic writing down of the mortgage balance could be considered.

In the second design, the principal of the mortgage is linked to the index, protecting homeowners against declines in house prices over the life of the mortgage. In order to avoid a liquidity constraint in the case of strongly increasing prices (unrealized gains on housing), we propose an asymmetric payoff profile: a put option is incorporated in the mortgage, in such a way that the principal is directly reduced by a potential negative index performance. The put premium is added to the periodic interest instalments. We estimate the put premium to be approximately $0.7 \%$ p.a. over a 5 year term, according to market conditions in Q1 2006.

\subsection{Index-Linkage Improves Credit Quality}

Traditional asset and liability management targets an immunization effect that smoothes the equity position and reduces default risk. The same effect applies to the portfolio of homeowners and to home equity. Combining mortgages with property derivatives effectively reduces the collateral's volatility with respect to the mortgage liability. This portfolio optimization reduces potential risk and has a direct impact on the price of index-linked mortgages. ${ }^{4}$

\footnotetext{
${ }^{3}$ These levels reflect the pricing practice in Switzerland.

${ }^{4}$ See Section 4
} 
Finance theory commonly splits debt instruments into a risk free part and a put option on the value of the collateral. This option is a so-called credit put. Its premium is charged as a credit spread on top of the risk free rate. In the case of mortgages, the bank sells an implicit out-of- the-money put option on the financed house. The strike price is equal to the nominal amount of the mortgage. The index-linked mortgage additionally contains an index option. This index option serves as additional collateral and therefore considerably reduces the loss given default. The effectiveness of this credit risk reduction depends on the correlation between the individual house price and the house price index. If this correlation is significantly positive, the bank's credit risk is considerably reduced. The result is a lower credit spread charged to homeowners, or, alternatively, a higher loan to value ratio. We describe the accuracy and efficiency of an index-hedge in the following section.

\section{Is an Index-Hedge Appropriate?}

The price of housing is subject to considerable fluctuations over time, which in turn lead to significant fluctuations in wealth. As pointed out by Sinai and Souleles (2003), the effects of house price risk on consumers' choices are ambiguous. For a household with utility defined over housing consumption, homeownership acts as a hedge against changes in the cost of consumption, i.e. against rent risk. Housing market risk may thus increase homeownership rates. The extent to which hedging considerations affect tenure choice is mitigated by the existence of frictions in the real estate and mortgage market. Transaction costs coupled with borrowing constraints restrict the number of house trades and investors' ability to implement first-best strategies significantly (Cocco, 2000). In this context, the existence of a liquid property derivative, such as the one described, is of great interest to investors. However, the extent to which an investor may take advantage of such a market is limited by its effectiveness for hedging purposes, i.e. by the amount of the idiosyncratic risk of individual properties compared to the risk of the overall market.

Results from previous research indicate substantial variability in returns to particular properties relative to the market. For the Swedish market, Englund, Hwang and Quigley (2002) 
report a standard deviation of the returns of individual properties of $11.3 \%$, compared with $7.6 \%$ for the market as whole. Goetzmann (1993) also documents a substantially higher variation for individual properties, with standard deviations 1.5 to 3 times higher for four US metropolitan areas. For New Zealand, Bourassa et al (2005) find standard deviations 1.4 to 2 times higher than the ones of the general market. They relate the degree of variation in price changes among houses within a market to their characteristics and to the prevailing conditions of the housing market at the time of the sale. Atypical houses and houses with characteristics in limited supply, for example waterfront houses, are generally more risky.

Unfortunately, the Zurich residential market is quite illiquid, with less than $2 \%$ of the housing stock traded each year. Even though our database covers around $20 \%$ of all transactions, we were able to identify only 264 repeated sales out of a total of 14'000 transactions. In our limited sample we measured a low correlation (0.19) between individual and market returns over a horizon of 4 years, rising to 0.38 over an interval of 8 years, and to 0.68 over 12 years. Although based on a very limited sample, these results are in line with the work of Iacoviello and Ortalo-Magné (2003) for London, who find a weakly positive correlation of 0.13 between the London housing returns and simulated individual returns at a short horizon (1 quarter) but a very strong correlation (0.87) at a 10-year horizon. In order to check for the robustness of our results we implement their methodology, adapted from Englund et al. (2002). The capital returns to a single housing unit, $r_{t}^{h}$ are defined as

$$
r_{t}^{h}=\left(p_{t}^{I}+\nu_{t}\right)-\left(p_{t-1}^{I}+\nu_{t-1}\right)
$$

where $p_{t}^{I}$ is the $\log$ of the house price index and $\nu$ is the idiosyncratic noise term with $E\left(\nu_{t}\right)=0$ and $E\left(\nu_{t}^{2}\right)=\sigma_{\nu}^{2}$. We take advantage of the availability of 11 geographically disaggregated indices for the Zurich area to approximate the returns on individual properties. We thus assume that the idiosyncratic variation of individual housing returns is captured by the variation of the local index returns around the returns of the market index. Note that this method is likely to underestimate true idiosyncratic risk, as the regional segmentation only represents one source of idiosyncratic risk. The estimated idiosyncratic volatility of the returns $\sigma_{\nu}$ is equal to 0.082 
while the volatility of the yearly index returns $\sigma_{I}$ is 0.054 . The correlations are indeed very high, ranging from 0.77 for 4 -year, to 0.89 for 8 -year and 0.96 for 12 -year periods.

In short, these partial and preliminary results confirm the importance of designing hedging instruments with maturities of at least 5 years, as correlations are higher at longer horizons.

\section{Pricing Index-Linked Mortgages}

We price an index-linked mortgage with an embedded put option such that the notional is directly reduced by a potential negative index performance. The pricing of a mortgage with index-linked interest payments is less demanding, since it represents only a replacement of linkage, while payoffs are still periodically realized. In addition to the pricing of the indexlinked mortgage, we are also interested in comparing the prices of index-linked mortgages with their traditional counterparts.

We represent each loan as a linear combination of financial instruments. More precisely, we divide the loan into the following securities: an unsecured loan, a credit derivative and, for the index-linked mortgage, a put option. This division follows the logic that an index-linked mortgage equals an unsecured loan plus a credit enhancement through a collateral, i.e. a credit derivative, plus an index put option. From a risk perspective, the risk factor in the unsecured loan is given by the default risk of the borrower, the risk factors of the credit derivative and of the put option are a combination of default risk and house price risk.

We assume that the pricing of the put option in the index-linked mortgages and the rating of the borrowers are given. We present the results below without proofs (for details see Akguen and Vanini (2006)).

We first consider a loan with a maturity of 5 years and fixed interest payments, secured by a collateral. The linear representation of the present value in terms of financial instruments reads 


$$
B^{Z_{b}}(0, T)=U^{Z_{u}}(0, T)+P D(0, T)\left(1+\frac{r_{T}}{n}\right)^{-n T} \gamma E[\min (E S, E F)]
$$

with $B^{Z_{b}}(0, T)$ the present value of the secured loan, $U^{Z_{u}}(0, T)$ the unsecured loan, i.e. the price of a loan depending on the borrower's non-collateralized creditworthiness. The second term represents the credit enhancement, i.e. a credit derivative. The annual, cumulated borrower's probability of default at maturity $T=5$ is denoted $P D(0, T)$, ES is the effective collateral, $E F$ the effective financing, i.e. the principal net of premature amortization, $r_{T}$ the risk free spot rate and $n$ the frequency of interest payments per annum, in accordance with the convention of $r_{T}$. Probability of default (PD) mainly depends on the income of the borrower. For simplicity, we therefore assume PD is independent from house prices. However, house price development drives the loss given default (LGD). PD and LGD together define the lender's loss characteristics and consequently, the required credit spread. Interest payments of the unsecured (secured) loan are denoted $Z_{u}\left(Z_{b}\right)$.

The implicit credit derivative reflects Swiss legal practice as follows: first, for the credit derivative to become effective, the borrower has to default $(P D(0, T))$. After a default, a fraction of the cohort of borrowers is able to recover. This fraction, which empirically ranges from $20 \%$ to $30 \%$ of all defaulted borrowers, is summarized by a fixed probability $1-\gamma$.

However, the fact that some borrowers do not recover explains the expression $\gamma$ in (2). Then, the collateral, according to the terms and conditions in the borrower's note, is exchanged with the financing liability. The bank receives the smaller of the two, i.e. $\min (E S, E F)$. The effective collateral, $E S$, reads

$$
E S=\min \left(S, \max \left((1-\beta) H_{T}+a_{S}-v, 0\right)\right)
$$

with $v$ the value of any senior liabilities, $H$ the value of the distrained object, $\beta$ the estimated percentage cost in the recovery workout, $S$ the value of the borrower's note and $a_{S}$ the value of other collateral than property. With

$$
\min (E S, E F)=E F-\max (E F-E S, 0),
$$


the present value of the loan reads

$$
\begin{aligned}
D^{Z_{b}}(0, T) & =U^{Z_{u}}(0, T) \\
& +\gamma P D(0, T)\left[\left(1+\frac{r_{T}}{n}\right)^{-n T} E F-\operatorname{Put}\left(E F, T, r, \sigma_{E S}, \mu_{E S}\right)\right],
\end{aligned}
$$

with Put(·) an European put option, $\sigma_{E S}$ the volatility of the collateral (property) and $\mu_{E S}$ the annual growth rate of the collateral.

In order to value this option it is assumed that the effective collateral follows a lognormal process. We then follow the approach in Schiller and Weiss (1999), which boils down to the Black-Scholes formula except that the underlying asset grows at a rate different than the riskless rate.

This loan-implicit put option should not be confused with the explicit put option in the index-linked contract discussed below.

For the explicit put option on the index it is important to note that this option is not valued in its entirety, but we are interested in the affect of this option on the loan condition. That is, if the borrower buys such an option this would amount to an effective increase in the collateral if the bank is contractually able to make use of the option payoff in case of default. We therefore calculate the improvement in the loan conditions that is brought about by this put option. For this, it is assumed that both the effective collateral and the index follow correlated lognormal processes, which are then simulated to determine the expected additional payoff from the put option.

Table 4 shows the prices of the loan contracts for 8 different rating classes, with class 8 the defaulted class. (all amounts are in Tsd. CHF). ${ }^{5}$

The two main conclusions from Table 2 are: first, the lower the creditworthiness of a borrower, the more expensive the terms for the unsecured loan. Second, the lower the cred-

\footnotetext{
${ }^{5}$ We have chosen the following parameters: $\beta$ is CHF 20'000 / CHF 625 '000 $=3.2 \%$, probability of recovery $1-\gamma$ is $30 \%$, volatility of the collateral $\sigma_{E S}$ is $6 \%$ and the growth rate of the collateral $\mu_{E S}$ is $1.5 \%$. For the risk free interest rates we used CHF Swap Rates as of October 25, 2005 and Moody's default statistics to obtain the credit risk dependent discount factors.
} 


\begin{tabular}{rrrrrrr}
\hline Rating & $\begin{array}{r}\text { Loan } \\
\text { Principal }\end{array}$ & $\begin{array}{r}\text { Estimated Value } \\
\text { of Property }\end{array}$ & $\begin{array}{r}\text { Value of } \\
\text { Borrower's Note }\end{array}$ & $\begin{array}{r}\text { Unsecured } \\
\text { Loan }\end{array}$ & $\begin{array}{r}\text { Collateral } \\
\text { Enhancement }\end{array}$ & $\begin{array}{r}\text { Terms of } \\
\text { Mortgage }\end{array}$ \\
7 & 500 & 625 & 500 & $14.21 \%$ & $8.54 \%$ & $\mathbf{5 . 6 7 \%}$ \\
6 & 500 & 625 & 500 & $8.20 \%$ & $3.68 \%$ & $\mathbf{4 . 5 2 \%}$ \\
5 & 500 & 625 & 500 & $5.55 \%$ & $1.43 \%$ & $\mathbf{4 . 1 2 \%}$ \\
4 & 500 & 625 & 500 & $4.43 \%$ & $0.47 \%$ & $\mathbf{3 . 9 6 \%}$ \\
3 & 500 & 625 & 500 & $4.25 \%$ & $0.32 \%$ & $\mathbf{3 . 9 4 \%}$ \\
2 & 500 & 625 & 500 & $4.04 \%$ & $0.13 \%$ & $\mathbf{3 . 9 1 \%}$ \\
1 & 500 & 625 & 500 & $3.95 \%$ & $0.05 \%$ & $\mathbf{3 . 9 0 \%}$
\end{tabular}

Table 2

Pricing of interest rate type mortgages. The final price consists of the unsecured loan and the collateral enhancement for the bank as a protection buyer.

itworthiness of the borrower, the more the bank (as protection buyer) is willing to pay for collateral.

If we consider index-linked mortgages, the standard case described above is modified as follows. First, the automatic amortization of the principal if the put ends in the money, i.e. the property index declined over the life of the mortgage, is equivalent to additional collateral. This results in the replacement of the term $\min (E S, E F)$ in (3) by $P$ :

$$
P=E\left[\chi_{\left\{I_{T}>K\right\}} \min (E S, E F)+\chi_{\left\{I_{T}<K\right\}} \min \left(E S+\frac{\left(K-I_{T}\right)}{K} N, E F\right)\right]
$$

with $K$ the strike price of the index put option, $I_{T}$ the value of the index at maturity, $\chi$ the indicator function and $N$ the notional amount of the mortgage.

Second, the client pays a put premium. For the best two rating categories 1 and 2, the put premium is approximately $0.7 \%$ p.a. for a 5 year term. ${ }^{6}$ For borrowers with lower creditworthiness, i.e. a higher risk that they will fail to pay the put premium periodically for the full contract period, the put premium is higher. The variation of the premium is shown in Table 3.

Table 3 compares the index-linked mortgage with the traditional one. The parameters are the same as for Table 2 with the following additional data for the put: correlation between the index and the collateral is estimated $75 \%$ and the strike of the index put is set equal to the initial value of the index, i.e. at $100 \%$.

\footnotetext{
${ }^{6}$ The price for the put option is consistent with the pricing practice used at the Zurich Cantonal Bank.
} 


\begin{tabular}{rrrr|rrr}
\multicolumn{5}{c}{ Standard Mortgage } & \multicolumn{3}{c}{ Index-Linked Mortgage } \\
\hline Rating & Unsecured & $\begin{array}{r}\text { Collateral } \\
\text { Enhancement }\end{array}$ & $\begin{array}{r}\text { Terms of } \\
\text { Mortgage }\end{array}$ & $\begin{array}{r}\text { Index } \\
\text { Put }\end{array}$ & $\begin{array}{r}\text { Credit } \\
\text { Enhancement }\end{array}$ & $\begin{array}{r}\text { Index-Linked } \\
\text { Mortgage }\end{array}$ \\
7 & $14.21 \%$ & $8.54 \%$ & $\mathbf{5 . 6 7 \%}$ & $1.09 \%$ & $0.15 \%$ & $\mathbf{6 . 6 1 \%}$ \\
6 & $8.20 \%$ & $3.68 \%$ & $\mathbf{4 . 5 2 \%}$ & $0.95 \%$ & $0.07 \%$ & $\mathbf{5 . 4 1 \%}$ \\
5 & $5.55 \%$ & $1.43 \%$ & $\mathbf{4 . 1 2 \%}$ & $0.88 \%$ & $0.03 \%$ & $\mathbf{4 . 9 7 \%}$ \\
4 & $4.43 \%$ & $0.47 \%$ & $\mathbf{3 . 9 6 \%}$ & $0.81 \%$ & $0.01 \%$ & $\mathbf{4 . 7 6 \%}$ \\
3 & $4.25 \%$ & $0.32 \%$ & $\mathbf{3 . 9 4 \%}$ & $0.72 \%$ & $0.01 \%$ & $\mathbf{4 . 6 6 \%}$ \\
2 & $4.04 \%$ & $0.13 \%$ & $\mathbf{3 . 9 1 \%}$ & $0.71 \%$ & $0.00 \%$ & $\mathbf{4 . 6 2 \%}$ \\
1 & $3.95 \%$ & $0.05 \%$ & $\mathbf{3 . 9 0 \%}$ & $0.71 \%$ & $0.00 \%$ & $\mathbf{4 . 6 1 \%}$
\end{tabular}

Table 3

Pricing of interest rate type mortgages and index-linked mortgages. Index-linked mortgages are always more expensive than interest rate type mortgages. But the lower a homeowner's creditworthiness, the less are the relative additional costs for the put option compared to the interest rate case.

Table 3 shows that uniform in the borrower's creditworthiness the terms of the index-linked mortgage are more expensive than for the classical one. But one observes that the bank's willingness to pay for the credit enhancement depends on the creditworthiness of the borrower: the higher the creditworthiness, the lower the compensation for the credit enhancement. The difference in the final terms between the two mortgages for the rating class 7 is $0.94 \%$ whereas the put premium is $1.09 \%$. This result is due to the following ideal assumptions: the loan makes $80 \%$ of the estimated house price and the borrower's note equals the value of the mortgage's principal. However, if the loan policy is tight, index-linked mortgages reduce refinancing risk essentially.

If we put the ideal assumption aside, index-linked mortgages not only reduce refinancing risk but also turn out to be more profitable for clients with a low creditworthiness. Table 4 considers the pricing if the borrower's note is reduced from a nominal value of CHF 500'000 to CHF 200'000.

It follows that the lower the creditworthiness of the borrower, the more valuable the index put option as additional collateral.

\section{Conclusion}

Today, individual homeowners are often largely overexposed to the asset class of real estate. An index-linked mortgage provides the chance to improve the balance of individual portfolios and 


\begin{tabular}{rrrr|rrr}
\multicolumn{5}{c}{ Standard Mortgage } & \multicolumn{3}{c}{ Index-Linked Mortgage } \\
\hline Rating & $\begin{array}{rrrr}\text { Unsecured } \\
\text { Loan }\end{array}$ & $\begin{array}{r}\text { Collateral } \\
\text { Enhancement }\end{array}$ & $\begin{array}{r}\text { Terms of } \\
\text { Mortgage }\end{array}$ & $\begin{array}{r}\text { Index } \\
\text { Put }\end{array}$ & $\begin{array}{r}\text { Credit } \\
\text { Enhancement }\end{array}$ & $\begin{array}{r}\text { Index-Linked } \\
\text { Mortgage }\end{array}$ \\
7 & $14.21 \%$ & $3.53 \%$ & $\mathbf{1 0 . 6 8 \%}$ & $1.09 \%$ & $0.99 \%$ & $\mathbf{1 0 . 7 8 \%}$ \\
6 & $8.20 \%$ & $1.52 \%$ & $\mathbf{6 . 6 8 \%}$ & $0.95 \%$ & $0.67 \%$ & $\mathbf{6 . 9 6 \%}$ \\
5 & $5.55 \%$ & $0.59 \%$ & $\mathbf{4 . 9 6 \%}$ & $0.88 \%$ & $0.26 \%$ & $\mathbf{5 . 5 8 \%}$ \\
4 & $4.43 \%$ & $0.19 \%$ & $\mathbf{4 . 2 4 \%}$ & $0.81 \%$ & $0.09 \%$ & $\mathbf{4 . 9 6 \%}$ \\
3 & $4.25 \%$ & $0.13 \%$ & $\mathbf{4 . 1 2 \%}$ & $0.72 \%$ & $0.06 \%$ & $\mathbf{4 . 7 8 \%}$ \\
2 & $4.04 \%$ & $0.06 \%$ & $\mathbf{3 . 9 9 \%}$ & $0.71 \%$ & $0.03 \%$ & $\mathbf{4 . 6 7 \%}$ \\
1 & $3.95 \%$ & $0.02 \%$ & $\mathbf{3 . 9 3 \%}$ & $0.71 \%$ & $0.01 \%$ & $\mathbf{4 . 6 3 \%}$
\end{tabular}

Table 4

Pricing of interest rate type mortgages and index-linked mortgages. If collateral is a scarce resource, the bank is willing to sell index-linked mortgages that include an explicit put option at similar conditions than interest rate mortgages to homeowner's with a low creditworthiness.

reduce the systematic risk of real estate in these portfolios. Institutional investors, on the other hand, can optimize their portfolios by getting exposure to real estate without actually owning property. Mortgage providers, e.g. banks, could therefore pass on parts of the risk of indexlinked mortgages to institutional investors through the use of property derivatives. We can assume that demand as well as supply for index-linked mortgages exists. Such discussion of real estate risk will probably facilitate the creation of a family of suitable indices. We believe that it is only a question of time until house prices indices that are widely accepted by markets and in which investors are comfortable to invest are established. However, it is unclear whether the amount of transactions will be large enough to create the demanded regional focus of indexes, addressing idiosyncratic aspects appropriately. Valuations based on the model of hedonic real estate pricing are increasingly used and widely accepted, and provide an appropriate basis for house price indices. On the product side, banks will have to offer a menu of options to cater for the individual needs of property owners and investors. Reasonable structures of index-linked mortgages include the linkage of the principal while keeping interest payments fixed, or fixing the principal while linking interest payments. Financial engineering will allow the creation of any combination of these structures.

\section{References}

Akguen A. and P. Vanini, 2006, "Loan Pricing", Working Paper, FINRISK and Swiss Finance Institute. 
Baesel, J.B. and N. Biger, 1980, "The Allocation of Risk: Some Implications of Fixed Versus Index-Linked Mortgages", The Journal of Financial and Quantitative Analysis, 15: 457-467.

Bourassa, S.C, D. Haurin, J. L. Haurin, M. Hoesli and J. Sun, 2005, "House Price Changes and Idiosyncratic Risk: The Impact of Property Characteristics", Working Paper, University of Geneva.

Campbell, J. Y., 2006, "Household Finance", Working paper, Harvard University.

Case, K.E., R.J. Shiller and A.N. Weiss, 1993, "Index-Based Futures and Options Trading in Real Estate", Journal of Portfolio Management, 19(2): 83-92.

Cocco, J., 2000, "Hedging Housing Price Risk With Incomplete Markets", Working Paper, London Business School.

Englund, P., M. Hwang and J.M. Quigley, 2002, "Hedging Housing Risk", The Journal of Real Estate Finance and Economics, 24(1-2): 167-200.

Flavin, M. and T. Yamashita, 2002, "Owner-occupied housing and the composition of the household portfolio", American Economic Review, 92(1): 345-362.

Goetzmann, W. N., 1993, "The Single Family Home in the Investment Portfolio", The Journal of Real Estate Finance and Economics, 6(3): 201-222.

Iacoviello, M. and F. Ortalo-Magné, 2003, "Hedging Housing Risk in London", The Journal of Real Estate Finance and Economics, 27(2): 191-209.

Shiller, R.J. and A.N. Weiss, 1999, "Home Equity Insurance", The Journal of Real Estate Finance and Economics, 19(1): 21-47.

Statman, M., 1982, "Fixed Rate or Index-Linked Mortgages from the Borrower's Point of View: A Note", The Journal of Financial and Quantitative Analysis, 17: 451-457. 